Original Article

\title{
ASSESSMENT OF CURRENT PRESCRIBING PATTERN AND COST ANALYSIS OF ORAL ANTI- DIABETIC DRUGS IN ELDERLY POPULATION FROM PUNGANUR REGION OF ANDHRA PRADESH
}

\author{
M. AKMAL ALI BAIG ${ }^{1}$, GIRENDRA KUMAR GAUTAM*2,3
}

1,2Bhagwant University, Sikar Road, Ajmer, Rajasthan 305004, India, ${ }^{3}$ Shri Ram College of Pharmacy, Muzaffarnagar, U. P, India

Email: dr.girendra@gmail.com

Received: 30 Mar 2021, Revised and Accepted: 17 May 2021

\section{ABSTRACT}

Objective: The main aim of the study is to analyze the prescribing patterns and cost-effective analysis of single therapy and combination therapy oral anti-diabetic drugs, awareness of patients about diabetes, medication and lifestyle modification in the geriatrics population.

Methods: A prospective study was carried out over a period of $12 \mathrm{mo}$ in the region of Punganur Andhra Pradesh. Type 2 diabetic patients who were on oral anti-diabetic drugs were enrolled in the study. A suitable data collection form was prepared and used to collect the required data. The demographic data, disease data and the utilization of various oral anti-diabetic agents were analyzed. About 800 patients were enrolled for the study from rural and urban areas in Punganur. Among the study population, 63\% (504) were males and 37\% (296) were females in the age group of $55 \mathrm{y}$ and above. The majority of patients were from urban areas $70 \%(560)$ and $30 \%(240)$ were from rural areas. About $78 \%$ of the patients have a history of diabetes more than $10 \mathrm{y}$ and $22 \%$ were more than $5 \mathrm{y}$ and less than $10 \mathrm{y}$.

Results: The present study found that type 2diabetes was prevalent in males than females. Results show two anti-diabetic drugs of single drug and fixed dose combination per prescription was more than the single anti-diabetic drug also found new prescription was observed more and cost of treatment was immense when compared to old prescription. Prescription pattern exposed Glibenclamide, Metformin, Glipizide and Glimepiride were the most common drugs used among the various oral antidiabetics. Currently, newer drug DPPi 4 inhibitors like Sitagliptin, Vildagliptin and Teneligliptin are used as single and combination with metformin were increased in prescription. Among the various oral antidiabetics prescribed, the cost of 2 drugs per prescription and newer anti-diabetic drugs like DPPi4 was high but cost analysis study revealed the availability low cost brands in market.

Conclusion: The study concluded that Prescription pattern and cost analysis of marketed anti-diabetic drug might be helpful for the professional to prescribe low cost effective medication.

Keywords: Anti-diabetic, Prescription, Elderly, Cost analysis, Teneligliptin

(C) 2021 The Authors. Published by Innovare Academic Sciences Pvt Ltd. This is an open access article under the CC BY license (https://creativecommons.org/licenses/by/4.0/) DOI: https://dx.doi.org/10.22159/ijpps.2021v13i7.41646. Journal homepage: https://innovareacademics.in/journals/index.php/ijpps.

\section{INTRODUCTION}

India has one of the largest populations of diabetes in the world. The International Diabetes Federation (IDF) estimates the number of people with diabetes in India will reach 80 million by the year 2025. A survey depicts that $4 \%$ of adults in India suffered from diabetes in the year 2000 and is expected to increase to $6 \%$ by the year 2025 . The World Health Organization (WHO) has projected that the global prevalence of type 2 diabetes mellitus will more than double from 5 million in 1995 to 300 million by 2025. Between 1995 and 2025, there will be a $35 \%$ increase in the worldwide prevalence of diabetes mellitus, from 4 to $5.4 \%[1,2]$.

Diabetes mellitus (DM) is a group of metabolic disorders characterized by hyperglycemia; is associated with abnormalities in carbohydrate, fat and protein metabolism; and results in chronic complications including microvascular, macrovascular, and neuropathic disorders. When the amount of glucose in the blood increases, e. g., after a meal, it triggers the release of the hormone insulin from the pancreas $[3,4]$.

Blood glucose levels are mainly determined by absorption of glucose from gut, uptake of glucose by peripheral tissues, hepatic glucose output and insulin secretion from pancreas. Various oral antidiabetic agents act by modifying the factors aiding in the control of hyperglycemia. The treatment of diabetes can be done with conventional oral hypoglycemic agents [5, 6].

Environmental factors such as Lifestyle factor in type 2 diabetes provide evidence that overeating, especially when combined with obesity is associated with the development of type 2 diabetes. Obesity probably acts as a diabetogenic factor in those who are genetically disposed to develop type 2 diabetes. Age factor is an important risk factor for type 2 diabetes. It is principally a disease of the middle-aged and elderly, affecting $10 \%$ of the population over the age of $65[7,8]$. Patients over $75 \mathrm{y}$ of age have a higher risk of developing multiple complications than the age group of 65-74. Older adults are at higher risk for developing type 2 diabetes because of the combined effects of increased insulin resistance and pancreatic islet dysfunction.

\section{MATERIALS AND METHODS}

Prescription pattern and cost analysis of anti-diabetic drugs

This was a cross-sectional, prospective, observational study carried out in Home based review of prescription in rural and urban area of Punganur region in Andhra Pradesh, Spanadana Hospital Punganur. Permission from institutional ethical committee was obtained prior to the conduct of the study from Dr Sundaram, Authority of Spanadana Hospital (Institutional Ethical committee No: IEC/SPH/2016/02). The sample size for this study was 800 patients (100\% confidence) in accordance with World Health Organization (WHO) manual to assess drug use in individual facilities [9]. It was a pilot study with duration of 12 mo in which 800 patients of diabetes of $55 \mathrm{y}$ and above receiving antidiabetic therapy for more than $1 \mathrm{y}$ was randomly selected for participation after fulfilling inclusion/exclusion criteria, Inclusion criteria are characteristics that the prospective subjects must included in the study were patients with $>55 \mathrm{y}$ of age, Study targeted the diabetic patient and 
patients with Diabetics with minimum of 5years included in this study. Exclusion criteria are those characteristics that disqualify prospective subjects frominclusion in the study of Patients having $<55$ y of age excluded from the study, Diabetic with seriously ill (mortality condition) and reluctance, Study limited to persons with co morbid conditions. After obtaining informed consent, sociodemographic data along with details of anti-diabetic drug therapy, duration of treatment and lifestyle modifications were recorded. In addition, cost of prescribed molecule of anti-diabetic versus trade name of drugs was analyzed from reliable source.

Average number of anti-diabetic drugs per prescription, percentage of the different class of anti-diabetic drug prescribed, commonest class and type of anti-diabetic drugs prescribed, percentage of antidiabetic drugs prescribed from essential drug list from WHO and Indian National Essential Drug List $[10,11]$. Patients were categorized with age, sex, rural and urban populated. The prescriptions were categorized as single and combination therapy.

\section{RESULTS}

\section{Demographic data of diabetic patient}

Fig. 1 summarizes the demographic characteristics of the patient who involved in this study. The age of patients was 55-75 and above in which male $63 \%$ female $37 \%$ from $30 \%$ of rural population and $70 \%$ of urban area.

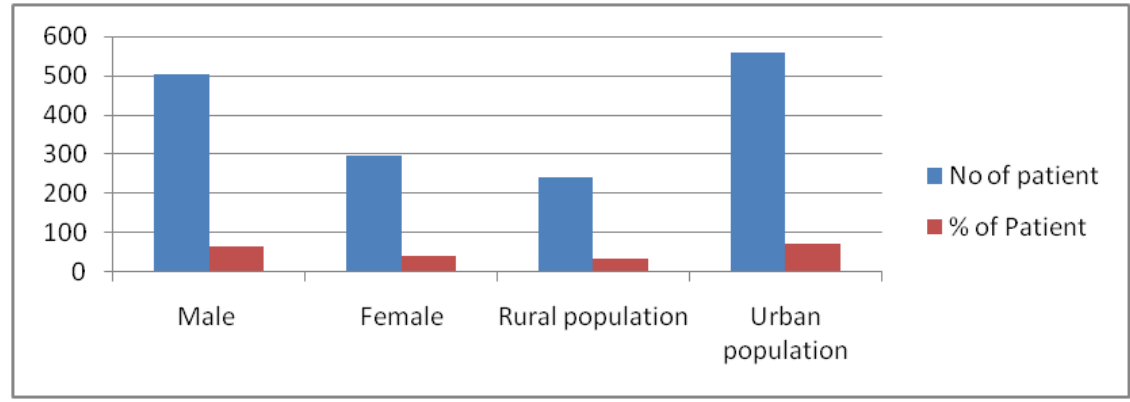

Fig. 1: Demographic Data of study population

\section{Prescription pattern of different classes of oral anti-diabetic drugs}

The different classes of oral anti-diabetic drug Sulfonylurea (SF), Biguanide (BG), Thiazolidinediones (TZ), Dipeptidyl peptidase-4 inhibitor (DPP-4i), Fixed-dose combination (FDC) of Sulfonylurea plus Biguanide, Sulfonylurea plus Thiazolidinediones, and Sulfonylurea plus Dipeptidyl peptidase-4 inhibitor was noted in prescription. The percentage of prescription for the single drug in class sulfonylurea and biguanide was $36 \%$ and $20 \%$ it was comparatively more than the sulfonylurea like Glipizide (8.37\%) Glimepride (12\%) and Pioglitazone (1\%). DPPi Sitagliptin and vildagliptin prescription was 1 and $3 \%$ of prescription and teneligliptin has $10 \%$ of total prescription.

FDC of Glimepride, Glipizide, Pioglitazone, Sitagliptin, Vildagliptin, Teneligliptin with Metformin prescription was $24 \%, 16 \%, 5 \%, 2 \%$ $13 \%$ and $9 \%$ respectively.

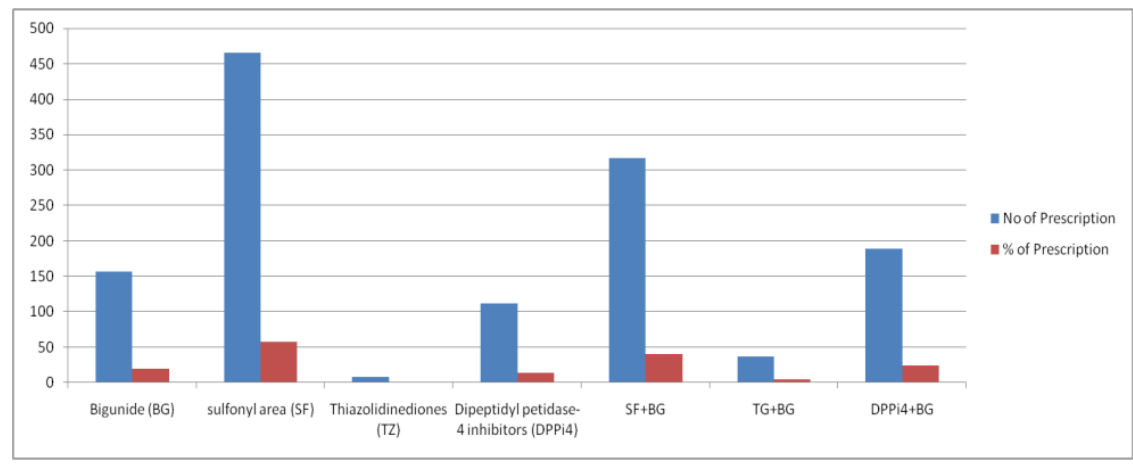

Fig. 2: Prescription pattern of Anti-diabetic drugs

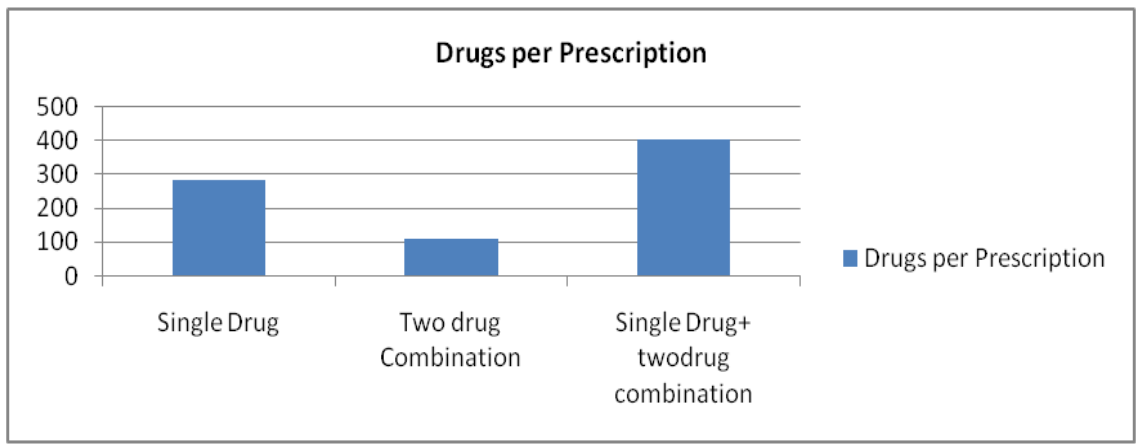

Fig. 3: Data showing the number of anti-diabetic drug per prescription 


\section{Oral Anti-diabetic drugs per prescription}

The fig. 3 shows three types of oral anti-diabetic medication per prescription such as single drug, two drugs and Single drug plus one fixed-dose combination (FDC) was $35.5 \%, 14 \%$ and $51 \%$ respectively.

\section{Co-morbidities of diabetic patient}

There are seven major disorders associated with diabetic patient revealed in fig. 4. Total of $112(14 \%)$ patients among the study population had associated kidney Disorder, Hypertension in 456 (14\%) patients, hyperlipidemia, in 128 (16\%), Vision Problem in 312 (39\%), a neurological disorder in 86 (11), Lung Disorder in 92 (12\%), the Liver disorder in $24(3 \%)$ and Diabetic foot 32 (4\%) was noted. In one Diabetic populated affected with two or more comorbidities.
Comparative cost analysis of oral anti-diabetic drug versus trade name

The following fig. 5-19 present the information of cost of different oral anti-diabetic drugs (OAD) available in different trade/brand names in India also in Andhra Pradesh. Cost of Different Brand of oral Anti-diabetic drugs treatment once a day for $360 \mathrm{~d}$ was calculated. The list of the drug in a different class of drug price was vary and in same classes of drug with brand name also were different some brand of same class was same also increased price was also listed. The following table shows the newer drugs like FDC teneligliptin, vildagliptin with metformin shows markedly more number of prescription since last two years, nowadays it will substituted by FDC of glimepride and glipizide at the same time cost of the treatment was high [12].

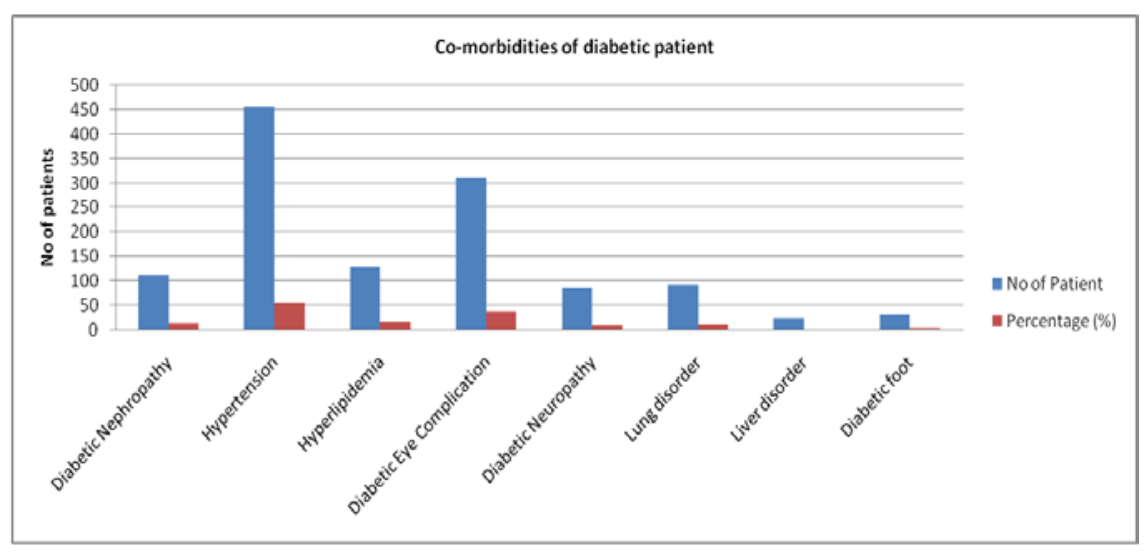

Fig. 4: Co-morbidities of diabetic patient

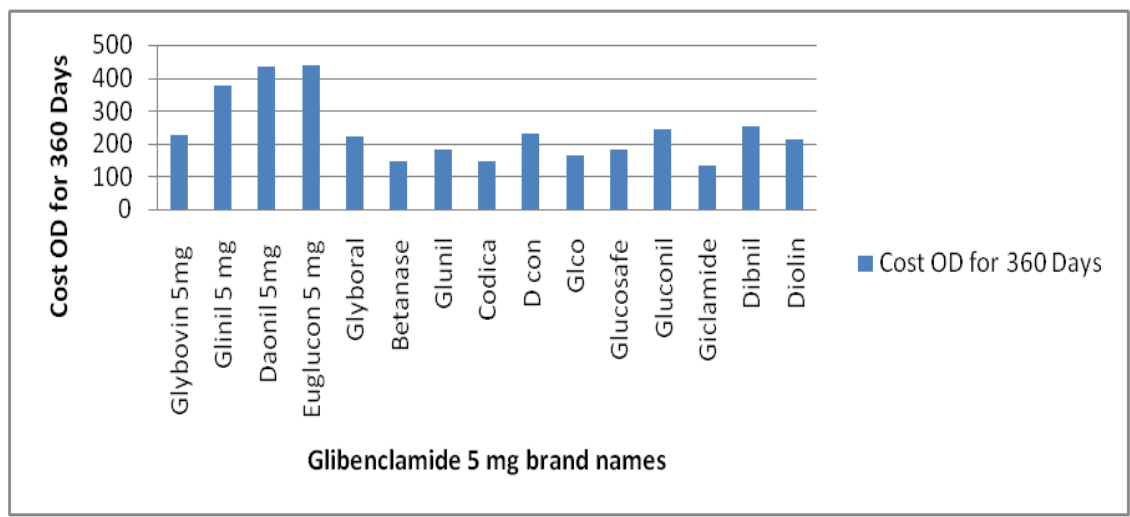

Fig. 5: Comparative cost analysis of glibenclamide versus trade name

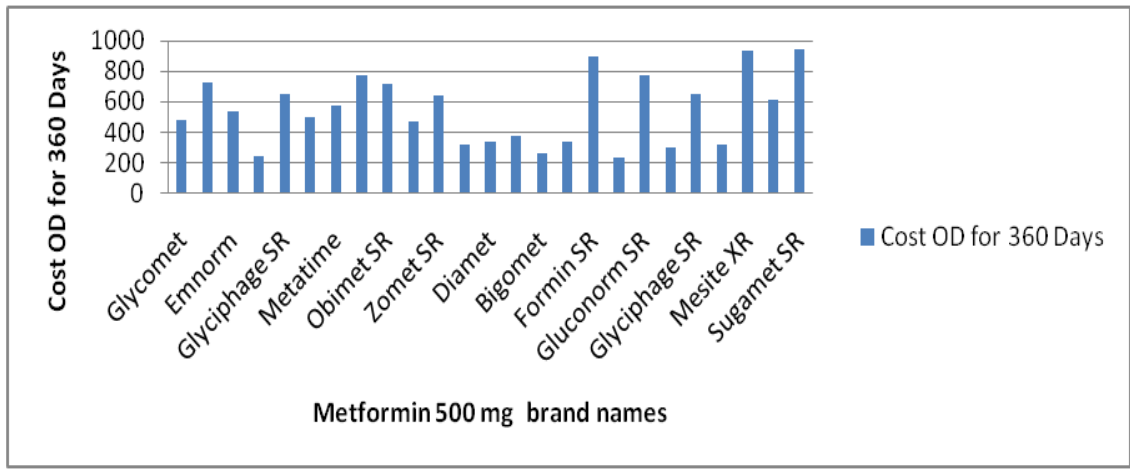

Fig. 6: Comparative cost analysis of metformin 500 mg versus trade name 


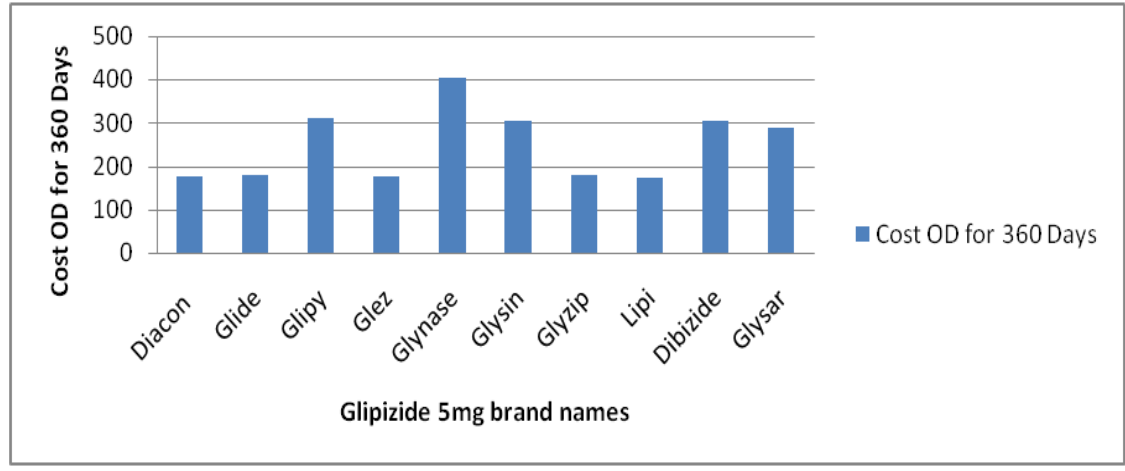

Fig. 7: Comparative cost analysis of glipizide 5 mg versus trade name

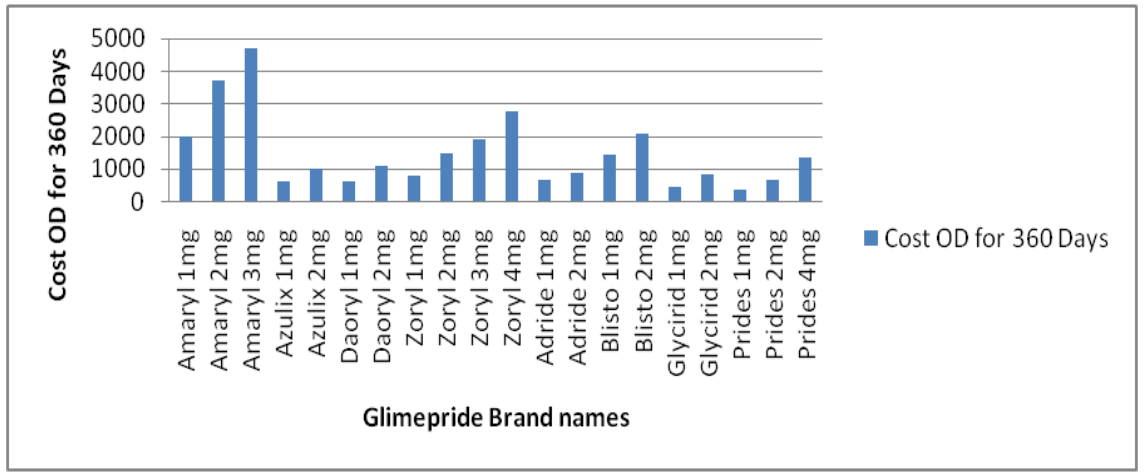

Fig. 8: Comparative cost analysis of glimepride versus trade name

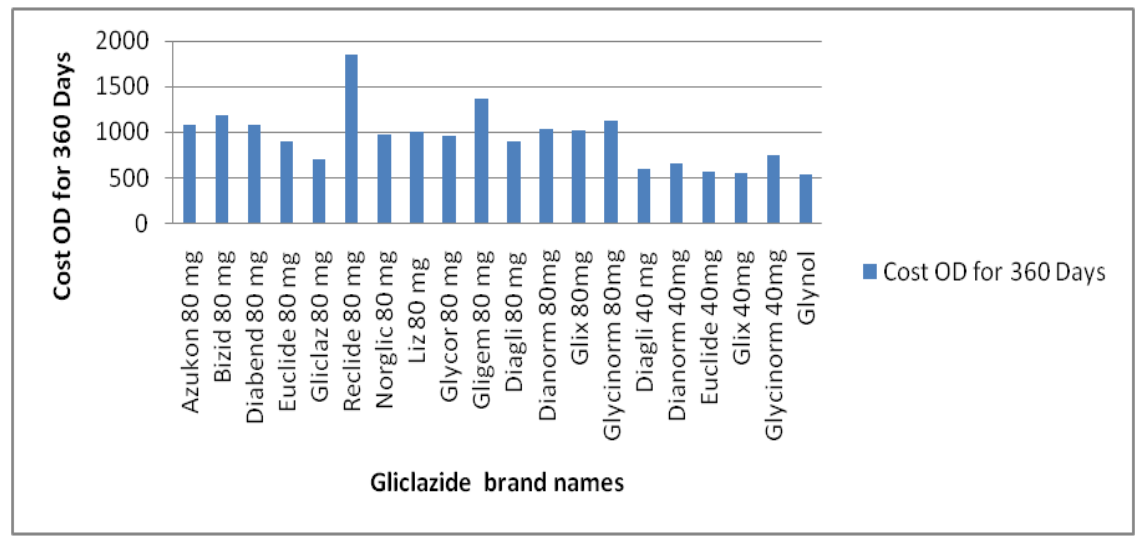

Fig. 9: Comparative cost analysis of gliclazide versus trade name

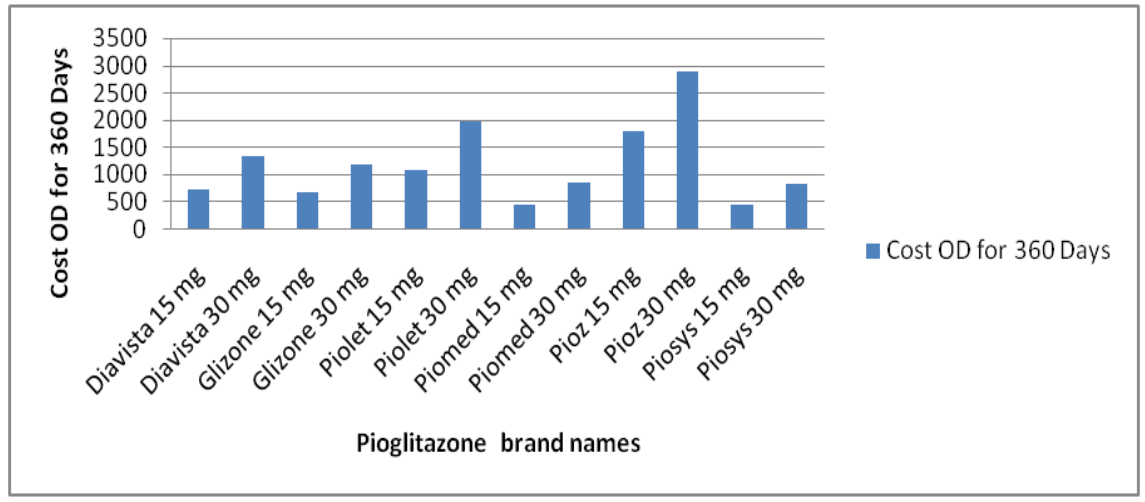

Fig. 10: Comparative cost analysis of pioglitazone versus trade name 


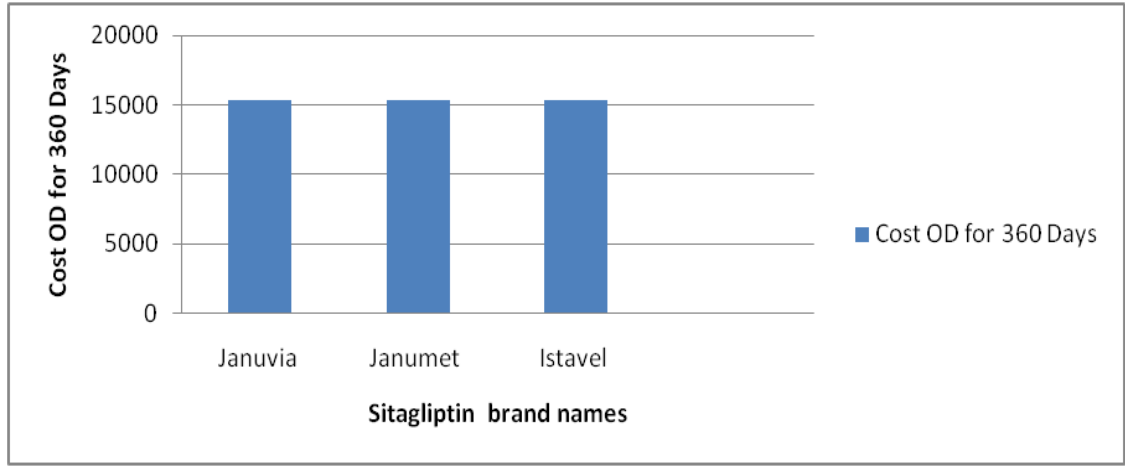

Fig. 11: Comparative cost analysis of sitagliptin versus trade name

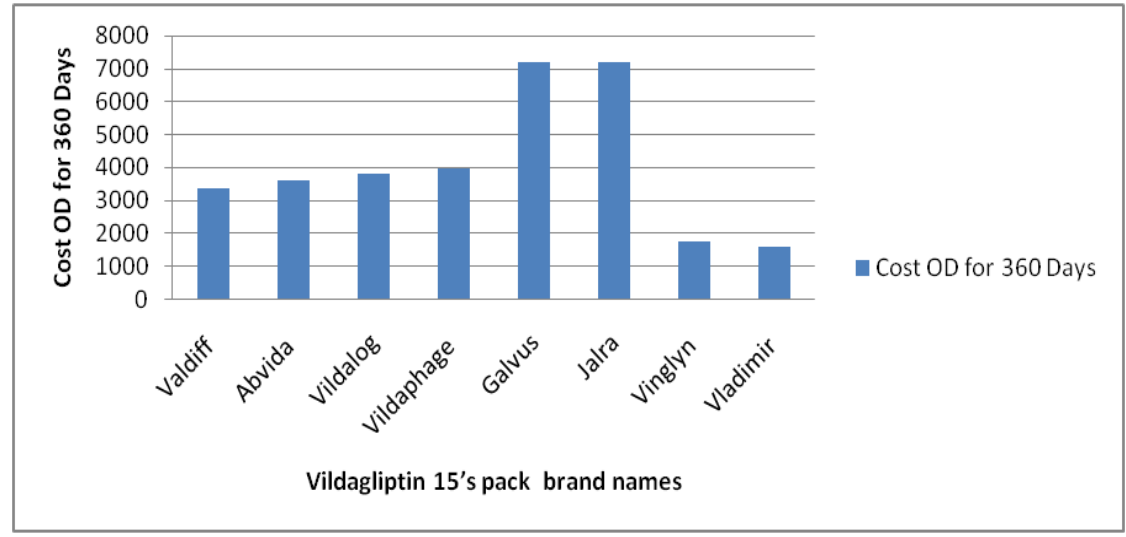

Fig. 12: Comparative cost analysis of vildagliptin versus trade name

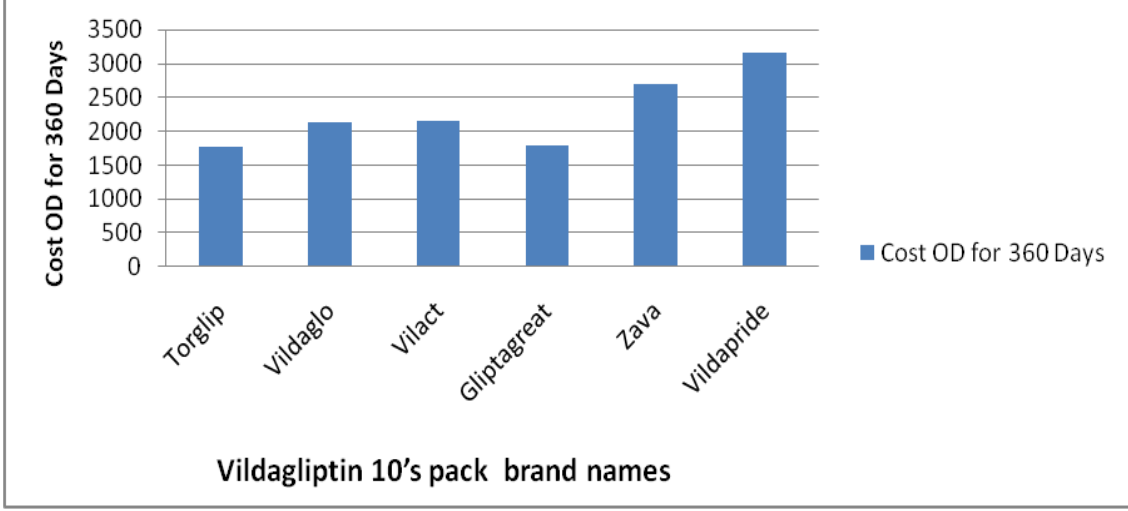

Fig. 12: Comparative cost analysis of vildagliptin versus trade name

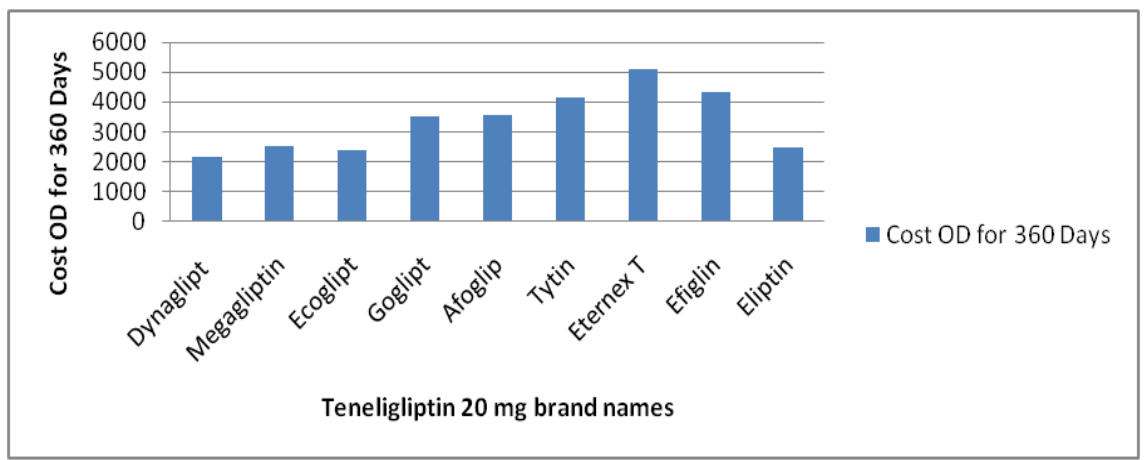

Fig. 13: Comparative cost analysis of teneligliptin $20 \mathrm{mg}$ versus trade name 


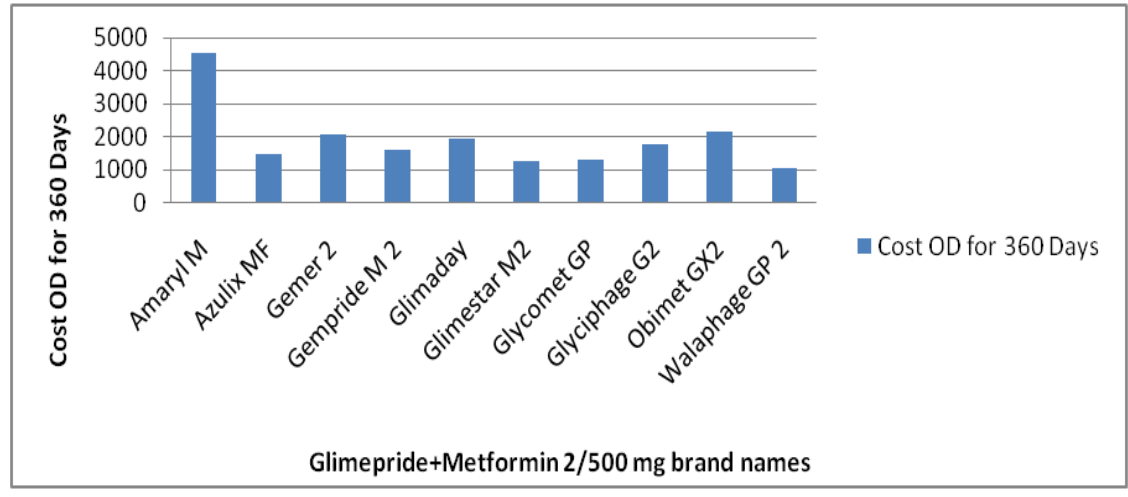

Fig. 14: Comparative cost analysis of glimepride+metformin 2/500 mg versus trade name

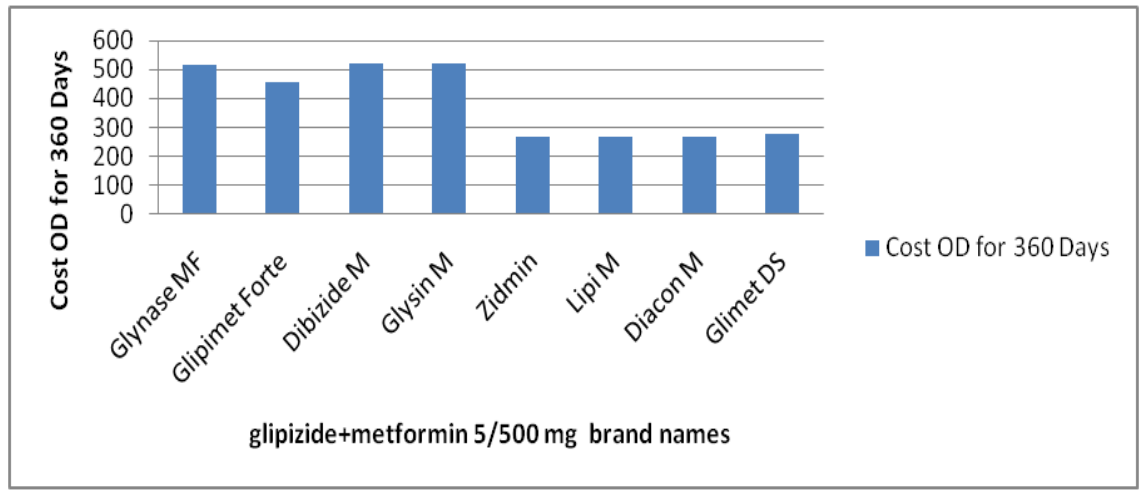

Fig. 15: Comparative cost analysis of glipizide+metformin 5/500 mg versus trade name

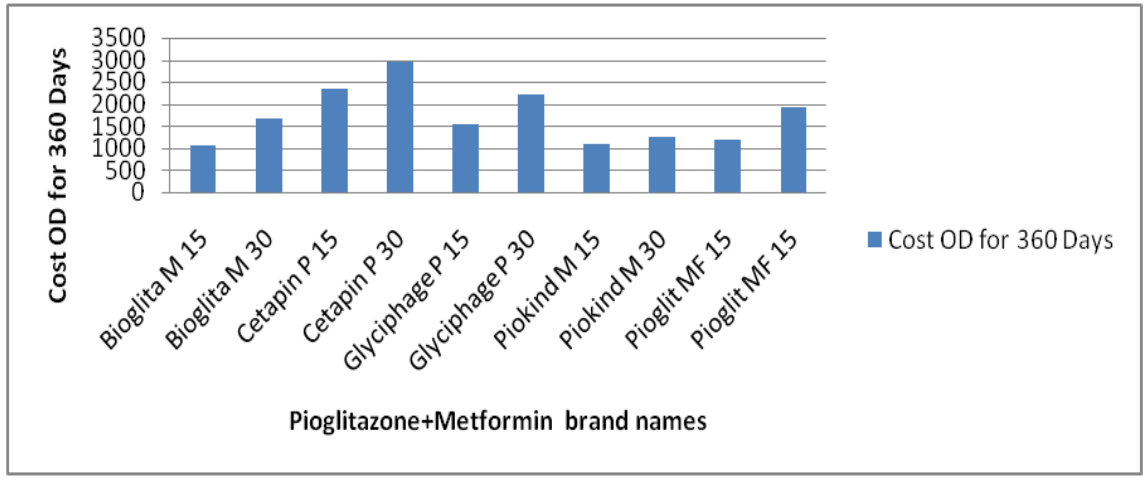

Fig. 16: Comparative cost analysis of pioglitazone+metformin versus trade name

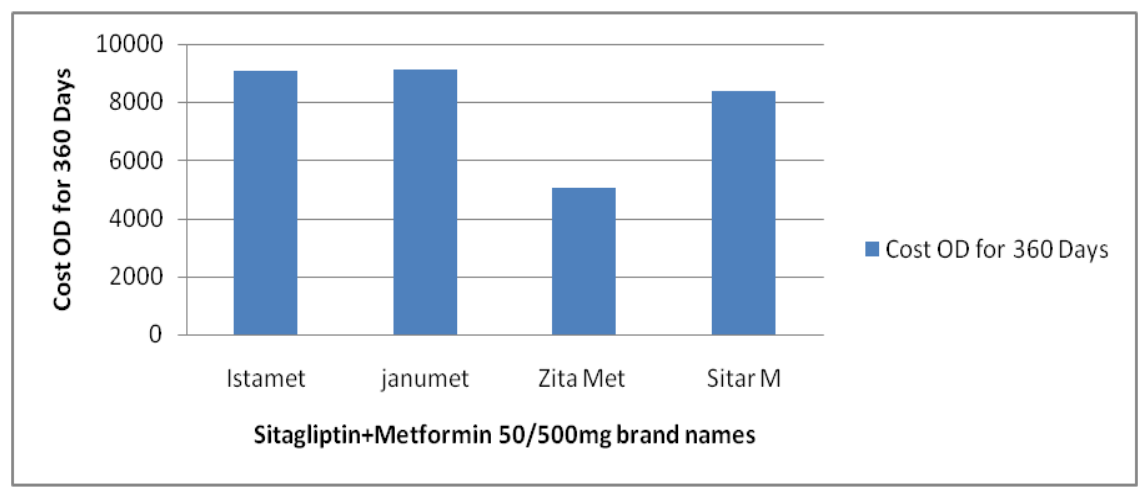

Fig. 17: Comparative cost analysis of sitagliptin+metformin 50/500 mg versus trade name 


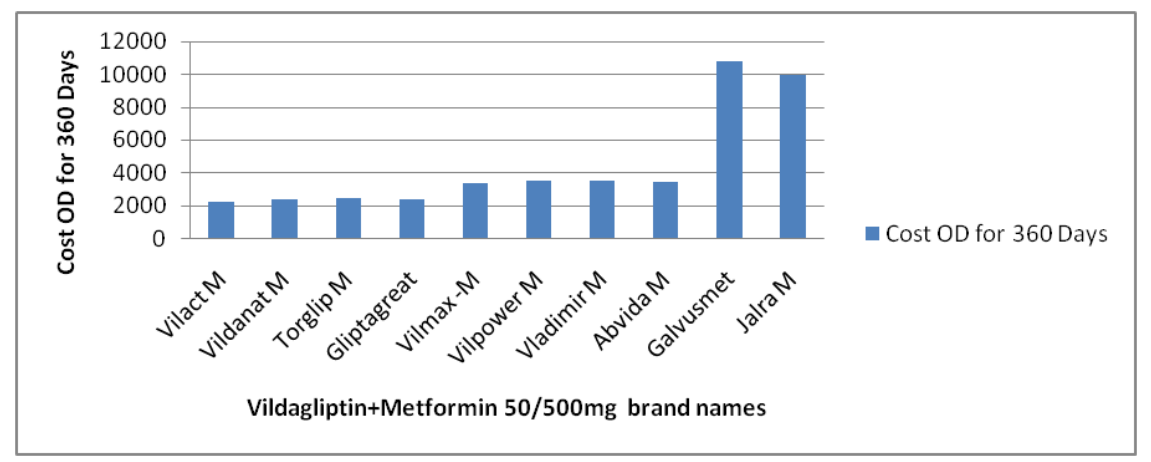

Fig. 18: Comparative cost analysis of vildagliptin+metformin $50 / 500 \mathrm{mg}$ versus trade name

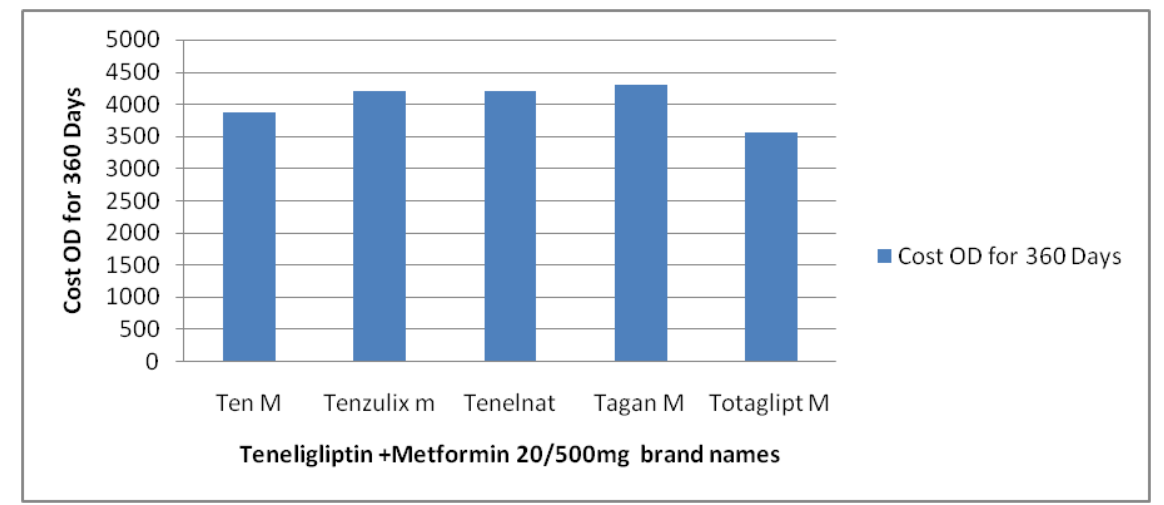

Fig. 19: Comparative cost analysis of teneligliptin+metformin $20 / 500$ mg versus trade name

\section{DISCUSSION}

The incidence of DM increases with aging. As a result, adults may be diagnosed incidentally after the age of 65 , or may have had a diabetes diagnosis in middle age or earlier onset. Having different demographic and clinical characteristics of these two groups may cause confusion caused by the setting of the general treatment recommendations. Age-related DM is characterized by lower A1C and the use of less insulin, with frequent occurrence in non-Hispanic whites. In comparison to adults with diabetes diagnosed in middle age, the retinopathy story is more prominent in late-onset diabetic cases, and interestingly there is no difference in the prevalence of cardiovascular disease (CVD) or peripheral neuropathy according to age at onset [13]. In diabetic adults increased development risk of lower extremity amputation, myocardial infarction (MI), impaired vision and end-stage renal disease. The present study result confirm the above statement of co-morbidities like diabetic nephropathy, Hypertension in diabetic patient

There are distinct classes of hypoglycemic agents such as biguanides, sulfonylureas, thiazolidinediones, and DPP-4 inhibitors. Describe their mechanism of action, to allow physicians to individualize and better treatment of diabetic people. Also provide cost-effective and economic treatment when patient condition was cotrolled by FDC of metformin+Glimepride or Glipizide or Pioglitazone instead of FDC of Metformin+Sitagliptin/Vildagliptin/Teneligliptin whis was high price medication

Biguanides are old agents that work by reducing hepatic glucose output and, to a lesser extent, enhancing insulin sensitivity in hepatic and peripheral tissues. In contrast to sulfonylureas, metformin does not directly stimulate insulin secretion; its major effects are to increase insulin action and insulin-mediated glucose utilization in peripheral tissues (such as muscle and liver), particularly after meals, and to decrease hepatic glucose output. thiazolidinediones act mainly by improving peripheral uptake and utilization of glucose in muscle and fat, finally decreasing liver glucose production [14-16]. DPP-4 rapidly degrades and inactivates
GLP-1, GIP, and other peptides in vivo via cleavage of N-terminal two amino acids. Inhibition of this enzyme leads to an increase in circulating endogenous GLP-1 and GIP levels. DPP-4 inhibitors mimic the therapeutic effects of incretin mimetics including stimulation of insulin secretion, inhibition of glucagon secretion, possibly preservation of b-cell mass and inhibition of apoptosis. These drugs display quite similar efficacy in lowering HbA1C (_1\% reduction) compared with other antihyperglycemic agents, but they are weight neutral and have a low potential for hypoglycaemia when used as monotherapy $[17,18]$.

Glucose intolerance increases progressively by aging and the characteristic feature of diabetes in elderly patients is especially postprandial hyperglycemia. Decrease in beta-cell-compensating capacity with advancing age, leads to insulin resistance and it appears as postprandial hyperglycaemia in the elderly [19]. Therefore, the prevalence varies according to the tests used during diagnosis on elderly patients. One-third of the individuals who are tested with $\mathrm{A} 1 \mathrm{C}$ or fasting plasma glucose (FPG) are cannot get a diagnosis [20].

The burden of treatment of older diabetic patients on the country economy is quite high. According to the analysis made in the in 2010 More than 14 million patients whose age 65 and over are hospitalized annually and approximately one-third of them are diabetic [21]. Again according to data, about 245 million is spent yearly on diabetes patients, of which 176 million is direct medical costs, while 69 million is the loss of production and mortality [22]. In addition, 59\% portion of the annual treatment costs has been made for elderly diabetic individuals. Most of the expenditures are caused by hospital admissions, home care and prescribed drugs, the extreme expenditures per person, depending on gender and age [23].

The present study shows that type 2 diabetes was more prevalent in males than females. The elderly patients were at high risk of developing type 2diabetes. A total of 800 patients had co-morbid conditions along with diabetes and commonly seen co-morbid conditions in the study were hypertension, impaired vision and 
renal disorder. The study has shown sulfonylurea and biguanide mainly metformin as the predominantly prescribed oral antidiabetic drug both in monotherapy and in combination therapy. Overall, monotherapy was found to be predominant over combination therapy. There was a significant increase in the prescriptions of newer oral antidiabetic agents like DPP-4 inhibitors. It may be concluded that the incidence of polypharmacy is increased when compared to olden days and the essential drug prescription is high and therefore drug use is quite rational. The present study also found that a number of new prescription combinations like metformin with sitagliptin, Vildagliptin and teneligliptin. Improving patient knowledge on correct medication will perhaps boost up the health care setting not only in hospital and outpatient setting also. The prescription pattern and cost analysis result shows single and fixed drug combination of prescription in diabetic geriatric patient. In starting day's single drug was used effectively for controlling of blood sugar level but now a day dual therapy along with single-drug therapy prescription was increased and also old drugs replaced by newer drug for effectively maintain the homeostatic condition of blood glucose level, at same time cost of the newer drug was high. It may influence the economical status of patient so effective prescription pattern may needed to improve cost-effective and economical status of geriatric. Comparatively high-cost availability of different brands were more but still low cost brand medication was also available it may helpful to reduce the economic burden of geriatric patient, mostly in patient with co-morbidity and also avoid potentially inappropriate medication in prescription.

\section{CONCLUSION}

Thus this study strongly highlights the cost analysis of different classes of diabetic drug with different available brand in market so that we can improve the patient's economical condition. Out of 800 patients no of patient from urban area was more when compared to rural area. It might be due to the life style modification in urban area. So educate the people for life style modification at the same time rural area the co-morbidity condition of diabetic foot was high. So it is must and important to educate the patient to protect foot away from injury and infections.

The current study concluded that due to current lifestyle modifications with single therapy alone cannot achieve a good glycemic control, a second drug selected among the sulfonylureas, thiazolinediones and DPPi 4 drugs must be used. To avoid therapeutic inertia, thus therapy should be modified into newer drugs like teneligliptin, metformin with DPPi 4 combination drugs shows in more prescriptions in the last few years to keep glycemic control. In this second step, various factors such risk of hypoglycemia, comorbidities, age of patients and presence of diabetic complications and cost of treatment must be properly considered to individualize treatment.

\section{FUNDING}

Nil

\section{AUTHORS CONTRIBUTIONS}

All the authors contributed equally in this research work. All authors read and approved the final manuscript.

\section{CONFLICT OF INTERESTS}

No conflict

\section{REFERENCES}

1. Dipiro TJ, Talbert LR, Materia Yee CG. Pharmacotherapy and pathophysiologic approach. 7 $^{\text {th }}$ ed. China: McGraw Hill Medical; 2008. p. 1206-37

2. Glenn M, Julie A. Diabetes mellitus and the metabolic syndrome. In Carol MP, Glenn M. Eds. Pathophysiology:-Concepts of altered health states. $8^{\text {th }}$ ed. China: Lippincott, Williams and wikins; 2008. p. 1047-69.

3. Kannan, Arshad, Kumar S. A study on drug utilization of oral hypoglycemic agents in type-2 diabetic patients. Asian J Pharm Clin Res 2011;4:60-4

4. Maithra A. The endocrine system. In: Kumar, Abbas, Aster, Fausto. Editors. Pathological basis of disase. $8^{\text {th }}$ ed. India; 2009. p. 1131-47.

5. Taylor C, Hobbs FD. Type 2 diabetes, thiazolidinediones, and cardiovascular risk. Br J Pharmacol 2009;59:520-4.

6. Roger Walker, Clive Edwards. Clinical pharmacy and therapeutics. 3rd ed Spain: Churchill Livingstone; 2003. p. 657-76.

7. Rayappa PH, Raju KN, Kapur A, Bjork S, Sylvest C, Kumar D. Ecomomic cost of diabetic care. Int J Diabetes Dev Countries 1999;19:87-97.

8. Haslett C, Chilvers RE, Boon AN. Davidson's principles and practice of medicine. 19th ed. London: Churchill Livingstone; 2003. p. 657-77.

9. How to Investigate Drug Use in Health Facilities: Selected Drug Use indicators. Geneva: Switzerland: World Health Organization (WHO) and International Network for Rational Use of Drugs; 1993.

10. National List of Essential Medicines of India. Ministry of Health and Family Welfare, Government of India; 2011. Available from: http://www.pharmaceuticals.gov.in/NLEM.pdf. [Last accessed on 20 Feb 2021]

11. WHO Essential Medicine List. World Health Organization; 2011.

12. http://www.medlineindia.com. [Last accessed on 20 Feb 2021]

13. Petersen KF, Krssak M, Inzucchi S, Cline GW, Dufour S, Shulman GI. Mechanism of troglitazone action in type 2 diabetes. Diabetes 2000;49:827-31.

14. Bailey J, Turner RC. Metformin N. Engl J Med 1996;334:574-9.

15. DeFronzo RA, Goodman AM. Efficacy of metformin in patients with non-insulin-dependent diabetes mellitus. The multicenter metformin study group. N Engl J Med 1995;333:541-9.

16. Bressler R, Johnson DG. Pharmacological regulation of blood glucose levels in non-insulin dependent diabetes mellitus. Arch Intern Med 1997;157:836-48.

17. Demuth $\mathrm{HU}$, McIntosh $\mathrm{CH}$, Pederson RA. Type 2 diabetes-therapy with dipeptidyl peptidase IV inhibitors. Biochim Biopsies Acta 2005;1751:33-4.

18. Chang AM, Halter JB. Aging and insulin secretion. Am J Physiol Endocrinol Metab 2003;284:E7-12.

19. Szoke E, Shrayyef MZ, Messing S, Woerle HJ, van Haeften TW, Meyer C, et al. Effect of aging on glucose homeostasis: accelerated deterioration of beta-cell function in individuals with impaired glucose tolerance. Diabetes Care 2008;31:539-43.

20. Solving E, Coresh J, Brancati FL. The burden and treatment of diabetes in elderly individuals in the $u$. s. Diabetes Care 2006;29:2415-9.

21. Weir LM, Pfuntner A, Steiner C. Hospital utilization among oldest adults, 2008. HCUP Statistical Brief 103. Agency for Healthcare Research and Quality, Rockville, MD; 2010.

22. American Diabetes Association. Economic costs of diabetes in the U. S. in 2012. Diabetes Care 2013;36:1033-46.

23. Zhuo X, Zhang P, Barker L, Albright A, Thompson TJ, Gregg E. The lifetime cost of diabetes and its implications for diabetes prevention. Diabetes Care 2014;37:2557-64. 